УдК 621.391

\title{
ПОВЫШЕНИЕ ЭФФЕКТИВНОСТИ СПЕКТРАЛЬНОГО АНАЛИЗА ПРИ НИЗКИХ ОТНОШЕНИЯХ СИГНАЛ/ШУМ С ИСПОЛЬЗОВАНИЕМ ТЕХНОЛОГИИ СУРРОГАТНЫХ ДАННЫХ БЕЗ СЕГМЕНТАЦИИ НАБЛЮДЕНИЯ
}

\author{
КОСТЕНКО П. Ю., ВАСИЛИШИН В. И.
}

Харьковский университет Воздушных Сил, Украина, Харьков, 61023, ул. Сумская 77/79

\begin{abstract}
Аннотация. Проведен сравнительный анализ двух методов оценки корреляционной матрицы (КМ) наблюдения, основанных на получении ансамбля его сегментов и псевдоансамбля, полученного применением технологии суррогатных данных. Показано, что в диапазоне малых отношений сигнал-шум ошибка оценки КМ с использованием псевдоансамбля меньше ошибки оценки КМ, использующей сегментацию наблюдения. Поскольку оценка КМ является базовой процедурой в современных методах спектрального анализа, в работе с использованием моделирования показано, что применение псевдоансамбля наблюдения позволяет отказаться от сегментации наблюдений, снижающей разрешающую способность спектрального анализа
\end{abstract}

Ключевые слова: суррогатные данные; спектральный анализ; собственноструктурные методы; коррекция; размер сегмента

\section{ВВЕДЕНИЕ}

До недавнего времени статистическая обработка сигналов в большинстве случаев основывалась на использовании асимптотических методов статистики, которые предполагают возможность получения либо большой выборки наблюдений, либо их ансамбля (повторные наблюдения). В то же время, в практике обработки сигналов это условие часто не выполняется. В результате использование асимптотических методов статистики становится малоэффективным.

В последнее десятилетие наблюдается интерес исследователей к возможности дополнения классических асимптотических методов статистики нетрадиционными компьютерно-ориентированными методами. Эти методы, получившие название «численного ресам- плинга» (resampling) и технологии суррогатных данных, позволяют формировать ансамбль так называемых «псевдовыборок», которые могут сохранять как статистические, так и динамические свойства наблюдений генеральной совокупности признаков гипотетического множества данных [1-6].

В большинстве известных случаев ансамбль псевдовыборок используется для оценки качества полученных статистических решений и проверки гипотез. Ниже показано, что при определенных условиях ансамбль псевдовыборок также может быть использован для уменьшения влияния шума в наблюдении при формировании оценки его ковариационной матрицы.

Для формирования ансамбля псевдовыборок используются два подхода. 